\title{
La estética barroca al servicio de un Estado inquisitorial
}

\author{
María Palacios *
}

La fiesta que estudiamos es la que se celebró en el Convento de San Pablo de la ciudad de Córdoba, entre los días 1 y 2 de julio de 1671. Fue organizada por el Tribunal del Santo Oficio de la Inquisición en Córdoba, siguiendo lo ordenado por el Supremo Consejo de la Santa General Inquisición, con ocasión de la canonización de Fernando III el Santo, rey de Castilla y de León. La Descripción de aquel solemne acto fue impresa aquel mismo año en Córdoba ${ }^{1}$.

De ella nos hemos servido por cuanto que nos permite apreciar hasta qué punto los inquisidores supieron aprovechar los recursos estéticos del Barroco al servicio de su propia visión del mundo y de los intereses de la propia institución inquisitorial.

\footnotetext{
* Profesora de Historia Moderna. Universidad Nacional de Educación a Distancia (UNED). Madrid.

1 Descripción del culto que al Santo Fiey don Fernando, tercero de Castilla, triunfador en el suelo, triunfante en el cielo, consagró el Santo Oficio de la Inquisición de Córdoba por indulto de N. Santísimo Padre Clemente X y de orden del Supremo Consejo de la Santa General Inquisición, el día de la Visitación de Maria Santísima, dos de julio de 1671. Pónele en manos de S.A., rendido a sus pies, Córdoba 1671. Registra la existencia de esta publicación E. Van der Vekene, en su Bibliotheca Bibliographica Historiae Sanctae Inquisitionis, I, Vaduz, Topos Verlag, 1982, pág. 264. Cita como fuente de su información a PALAU, A., Manual del librero hispano-americano, 2, ${ }^{a}$ edición, ref. 70758 , sin dar noticia de la existencia de ningún ejemplar de este folleto. Nosotros hemos utilizado el ejemplar que se custodia en la Biblioteca de la Real Academia de Bellas Letras y Nobles Artes de Córdoba. Sobre este mismo tema, cfr. nuestros trabajos «Una fiesta barroca organizada por la Inquisición de Córdoba en honor de San Fernando", en / Congresso Internacional do Barroco, vol. Il. Porto 1991, págs. 207-220 y «El texto y la pervivencia de las imágenes. La descripción de la decoración efímera de una fiesta inquisitorial" (Comunicación presentada al Congreso Text und Bild in Dialog. Passau (Alemania) 1991, e.p.).
} 
Este tipo de publicaciones inquisitoriales, que Van de Vekene identifica como "escritos ocasionales"?, no abundaron demasiado o, por lo menos, no se dieron a la estampa con la frecuencia y el interés con que se editaron las Relaciones de Autos de fe. Aunque, como pronto veremos, todos los tribunales inquisitoriales del país organizaron, en las capitales de sus respectivos distritos, fiestas semejantes en honor de San Fernando, sólo los tribunales de Córdoba y de Granada estamparon Descripciones de los actos celebrados ${ }^{3}$.

Sabemos que los Tribunales de distrito organizaban solemnes actos públicos por diversos motivos; muy pocos son, sin embargo, los testimonios impresos de su desarrollo. Ni siquiera los actos celebrados con ocasión de las exequias de los Reyes o de los Príncipes tienen su reflejo en publicación alguna, al menos en las Inquisiciones de la España peninsular; por el contrario, al otro lado del Atlántico sí que se dieron a la imprenta diversas descripciones de exequias, como las celebradas por la Inquisición de Méjico en honor de Felipe $1{ }^{4}$ y del Príncipe Baltasar Carlos $^{5}$, o la promovida, en las exequias de este mismo príncipe, por la Inquisición del Perú ${ }^{6}$.

En este mismo aspecto, los usos de la Inquisición portuguesa se revelan diferentes de los de la española. Nunca la española editó oraciones fúnebres ni relaciones de las exequias de sus propios Inquisidores Generales. La portuguesa, sin embargo, dio a luz varias publicaciones de este género, como las oraciones fúnebres pronunciadas por Manuel Fe-

2 Der Vekene, E. Van, Op. cit., pág. 254.

3 Así, por lo que se refiere al Tribunal de Granada, la Descripción de la aclamación sumptuosa y célebre solemnidad que el Santo Tribunal de la Inquisición de Granada consagró don Fernando el Tercero en la fiesta de su veneración. Granada, Francisco Ochoa, 1671. De este folleto, sin embargo, no hemos localizado ningún ejemplar, siéndonos conocido exclusivamente por las referencias de Van der Vekene quien, a su vez, toma sus noticias del mencionado Palau.

${ }^{4}$ Ribera Flores, Dionisio de, Relación historiada de las exequias funerales de la Majestad del Rey don Felipe II, nuestro señor. Hechos por el Tribunal del Santo Oficio de la Inquisición de esta Nueva España y sus provincias y islas Filipinas, asistiendo solo el Licenciado don Alonso de Peralta, inquisidor apostólico y dirigida a su persona por el doctor... Méjico, Pedro Balli, 1600.

5 Pira sacra, memoria ardiente, real mausoleo que en las exequias y funeral pompa del señor don Baltasar Carlos de Austria, Príncipe jurado de las Españas, erigió el Tribunal santo de la Inquisición de Méjico, en el muy religioso y real Convento de Santo Domingo. Méjico, I. Ruiz, 1647.

- Álvarez de Faria, Pedro, Relación de las funerales exequias que hizo... la Inquisición de los Reyes del Perú al Serenísimo Príncipe de las Asturias, jurado de las Españas, don Baltasar Carlos de Austria. Lima, J. Santos de Saldaña, 1648. 
rreira, en Lisboa y por Antonio Vel, en Évora, en las exequias del inquisidor General don Francisco de Castro ${ }^{7}$.

Así pues, la singularidad de un relato como aquél que nos sirve de base para nuestra aproximación al Barroco, será un aliciente más para estudiarlo atentamente y darlo a conocer. Nuestro propósito será, en primer lugar el de fijar el marco histórico en que se encuadró esta espectacular fiesta barroca. En segundo lugar, pasaremos a la descripción escueta de los actos que integraron esta celebración. En tercer lugar, describiremos las decoraciones efímeras que, en aquella ocasión, se levantaron en el recinto de la Iglesia y en el claustro de san Pablo de Córdoba, escenario de esta celebración. Finalmente, en cuarto lugar, trataremos de captar cuál fue el mensaje que se intentó comunicar al pueblo mediante todo el material didáctico, tanto plástico como literario, que desplegó la Inquisición cordobesa en una ocasión para ellos tan importante.

\section{EL MARCO HISTÓRICO}

El Siglo del Barroco fue también el siglo de las canonizaciones. A lo largo del mismo, los papas declararon oficialmente la santidad de numerosísimos católicos, entre los que, sin duda, los más numerosos fueron los españoles. Famosa fue la hornada de santos canonizada en 1622, fecha en que subieron a los altares, entre otros, santa Teresa de Jesús, san Ignacio de Loyola, san Francisco Javier y san Isidro labrador.

La canonización, sin embargo, no significó exclusivamente el reconocimiento oficial de los méritos religiosos extraordinarios de los canonizados. Las canonizaciones fueron también un instrumento del que se valieron los reyes de la catolicidad para prestigiar y optimizar la «imagen pública” de sus respectivos Estados. Los papas favorables a la Monarquía Hispánica canonizaron gustosamente a los españoles. Pero, cuando

7 Ferreira, M., Oraçôens funebres nas Exequias que o Tribunal do Santo Oficio fez ao Illustrissimo \& Reverendissimo Senhor Bisbo D. Francisco de Castro, Inquisidor Geral destes Reynos... no Convento de S. Domingo de Lisboa a 15 de Janeiro de 1653. Lisboa, Of. Craesbeckiana, 1654. VEL, A., Sermâo prégado nas exequias que o Tribunal do Sancto Officio fez na morte do Illustrissimo Inquisidor Geral D. Francisco de Castro em 30 de Janeiro de 1653 no convento de S. Domingos d'Evora. Lisboa, Of. Craesbekiana, 1654. 
los avatares de la política enfrentaron al rey de España y a los pontífices, la vorágine canonizadora sufrió notables frenazos. Tal ocurrió bajo el pontificado de Urbano VIII, quien, como bien se sabe, inclinó decididamente la política de la Santa Sede a favor de Francia y en contra de España. Esa actitud hostil también se reflejó en lo que podríamos llamar "política de canonizaciones".

Así sucedió cuando España trató de promover la canonización de una nueva tanda de compatriotas. A partir de 1629, se proponen como candidatos al carmelita Juan de la Cruz, al beato Simón de Rojas, al cardenal Cisneros, al inquisidor Pedro Arbués y al rey Fernando III, entre otros. Por lo que a este último se refiere, el propio rey Felipe IV había declarado cuánto le interesaba al reino «ver uno de sus reyes en el Catálogo de los Santos, requisito que faltaba a la grandeza de esta Monarquía». Pero los vientos romanos soplaban en contra de los deseos del rey de España.

El papa, de momento, prohibió canonizar a nadie que hubiera muerto en los últimos cincuenta años. Aplicar este criterio significó excluir a Juan de la Cruz y a Simón de Rojas. Decidió también el papa excluir a quienes hubiesen recibido ya algún tipo de culto, aunque esto viniera ocurriendo desde «tiempo inmemorial». Con esta otra puntualización, se sacaba, igualmente, de la lista de candidatos, al rey Fernando III. Abundando en su idea, decidió finalmente el papa que, en adelante, no se canonizaria más que en tandas de cuatro santos, como mínimo, cada vez. Al mismo tiempo, ordenó que las sesiones en que había que estudiar y decidir sobre cada canonización se distanciaran entre sí mediante períodos mínimos de seis meses. Al parecer, el papa estaba dispuesto a dejar a los españoles que aspiraban a la santidad oficial sin su principal mérito: El de venir recomendados por el Rey Católico.

Todo quedó, en consecuencia, paralizado, hasta 1644, fecha en que subió al trono pontificio el papa Inocencio $X$, favorable a los intereses de los españoles. El nuevo papa revocó las disposiciones dadas por su antecesor, con lo que quedó desbloqueado el proceso de canonización de Fernando III. Pero el desenlace final del mismo sólo se produjo en tiempos de otro papa igualmente favorable a España, Clemente $X$, quien reconoció el culto público a san Fernando en febrero de 1671.

La decisión papal fue comunicada a doña Mariana de Austria, reinagobernadora de la Monarquía española durante la minoría de edad de Carlos II, quien a la sazón, aún no había cumplido los diez años ${ }^{8}$. La

\footnotetext{
` Había nacido el 6 de noviembre de 1661
} 
bula papal autorizaba a celebrar anualmente la fiesta de san Fernando el día 30 de mayo y, excepcionalmente, autorizaba también que se festejara aquel acontecimiento de forma especial dentro del año de 1671, en la fecha que pareciera más conveniente ${ }^{9}$.

De acuerdo con el texto de la bula papal, la reina-gobernadora ordenó a todas las Iglesias de la monarquía que celebrasen aquel acontecimiento con el mayor esplendor y exhortó a los cabildos municipales a concurrir a los actos que cada Iglesia programara ${ }^{10}$. Además, pero ya por iniciativa propia, ordenó que celebraran fiestas semejantes cada uno de los Consejos que integraban el gobierno del Estado.

Esta orden llegó también al Consejo de la General y Suprema Inquisición y éste, a su vez, mandó, mediante una carta acordada dirigida a todos y cada uno de los tribunales de distrito, que organizaran otras tantas fiestas en las ciudades donde radicaban.

«Ha parecido, —se decía en la carta del Consejo-, ordenaros que en un día, el que os pareciere, como sea después del referido 15 de junio, hagáis esta fiesta al santo rey en la iglesia donde se suelen celebrar las demás festividades por ese Tribunal, conforme a lo que se hizo en la del beato Pedro de Arbués» ${ }^{11}$.

La carta salió de Madrid el día 4 de mayo de 1671. A Córdoba debió llegar once días después, tiempo que, regularmente, necesitaba el correo para cubrir la distancia entre Madrid y Córdoba. Así, entre el 15 de mayo y el 30 de junio, el Tribunal dispuso de cuarenta y cinco días para organizar la fiesta que se iba a celebrar a primeros de julio.

Todavía unos días después, el 1 de junio, el Consejo emitió una segunda "Carta acordada», complemento de la anterior, en la que precisó en qué debian consistir las fiestas que se habían ordenado. Según ello, sólo debería programarse "con misa, música y sermón». Tanto el altar como la iglesia deberían engalanarse «con el ornato necesario». Se permitía que, en la víspera de la fiesta, durante la noche, su pusieran luminarias. Pero se prohibía expresamente que, con tal ocasión, se quemaran castillos de pólvora o cualquier otro género de fuegos artificiales ${ }^{12}$.

\footnotetext{
${ }^{9}$ Cfr. Bula papal en Apéndice I.

${ }^{10}$ Cfr. Apéndice III.

${ }^{11}$ Cfr. Apéndice I.

${ }^{12}$ Cfr. Apéndice IV.
} 


\section{2. "DESCRIPCIÓN DEL CULTO»}

Los actos que programó el Tribunal Inquisitorial de Córdoba, en cumplimiento de estas órdenes, se desarrollaron de la forma siguiente.

A mediodía del primero de julio, «se hicieron lenguas las campanas de la insigne catedral y de todos los conventos e iglesias de esta ciudad» ${ }^{13}$. La fiesta comenzaba. A las cinco de la tarde, salió un lucido cortejo de los Reales Alcázares, es decir, el actual alcázar de los Reyes Cristianos, en cuyo recinto estaba aposentado el Tribunal de la Inquisición cordobesa.

Abrían el paso unos trescientos soldados armados, todos ellos miembros de la llamada "Compañía de los Reales Alcázares", con su capitán al frente ${ }^{14}$. Seguían a los soldados hasta un centenar de ministros de la Inquisición, todos ellos a caballo, precedidos por D. Juan Ramón de Góngora y Argote, quien llevaba el estandarte de san Pedro Mártir, titular de una cofradía a la que pertenecía todo el personal de la Inquisición ${ }^{15}$. Marchaban, tras ellos, los caballeros familiares de la Inquisición, acompañando al estandarte de san Fernando:

«Labróse estandarte - se lee en la crónica- para esta solemnidad, ricamente bordado sobre raso blanco. En el reverso, la efigie del santo rey, ceñida de esta letra: Regnum meum non est de hoc mundo; y en el otro, la santa cruz, timbre que coronó sus victorias, con mote más debido que al lábaro: In hoc signo vici ${ }^{16}$.

Una hora tardó el lucido cortejo en hacer el camino entre los Reales Alcázares y el convento de san Pablo el Real, «monasterio del orden del glorioso patriarca español santo Domingo de Guzmán y fundación del

${ }^{13}$ Descripción..., pág. Aa.

${ }^{14}$ Integraban esta compañía, en su mayor parte, los vecinos de la barriada de San Basilio, que ocupaba el ángulo suroeste de la ciudad en aquella época y que se extiende desde la vecindad de los Reales Alcázares hasta la puerta de Sevilla, en un espacio rodeado de murallas conservadas hoy día en su mayor parte.

${ }^{15}$ Se trata de la Cofradía de San Pedro Mártir de Verona que venía experimentando un extraordinario desarrollo desde el reinado de Felipe III.

${ }^{16}$ Descripción..., op. cit., pág. Av. 
Santo Rey", por las mismas calles por las que solían discurrir las procesiones inquisitoriales para los Autos de fe ${ }^{17}$.

Una vez en el templo, se procedió a cantar unas solemnes vísperas.

«Alternó - se cuenta - la capilla de la Catedral en dulcísimas voces el himno de las alabanzas de Dios... Continuó la música, con la dulzura misma, un villancico en que esta vez, contrarias, se compitieron la valentía de las Musas y la destreza de Orfeo" ${ }^{18}$.

En una pausa, los mayordomos de la cofradía de san Pedro Mártir pasaron «repartiendo estampas del santo Rey don Fernando a todos los ministros, hermosas como del dibujo del Apeles de España, Bartolomé Morillo" ${ }^{19}$. En esto, “los instrumentos músicos y una salva real de mosquetería rompieron el aire", al tiempo que se dejó caer, desde el techo de la iglesia, una densa lluvia de estampas y «cedulillas de conceptuosos versos de alabanza del santo Rey" ${ }^{20}$. Puede imaginarse el alboroto que se formaría cuando los asistentes, chicos y grandes, se abalanzaran para recogerlas.

Acabadas las vísperas, los cantores entonaron «la suave diversión de unas sazonadas quintillas» "21, con las que se cerró el acto. El cortejo regresó a los alcázares, ya de noche, por las mismas calles por las que había venido: unas calles cuyos vecinos habían iluminado profusamente, a petición del corregidor de Córdoba ${ }^{22}$.

Al día siguiente, 2 de julio, «rompieron la alborada las campanas» al tiempo que se dispararon cohetes de pólvora que estallaban en la altura con estruendo.

17 Ibidem.

${ }_{18}$ Ibidem. Descripción..., pág. Av.

¿ La referencia a Bartolomé Esteban Murillo parece ser obvia. No conservamos ejemplares de aquellas estampas, pero podemos suponer que la imagen impresa pudo haber sido grabada a partir de alguno de los cuadros de san Fernando que Murillo pintó, de los que se difundieron numerosas copias por toda Andalucia.

${ }^{20}$ Descripción..., pág. Aa.

${ }^{21}$ Cfr. Apéndice VIII.

${ }^{22}$ Descripción..., pág. Aa. 
«Se hizo también lenguas el fuego, subiendo con voladoras alas a abrazarse con su región, para que el cielo y tierra concurriesen a la celebridad" ${ }^{23}$.

Un cortejo semejante al que hizo la procesión de la víspera recorrió el mismo itinerario. La comunidad de dominicos salió a recibirlo a la puerta de san Pablo. Se expuso el Santísimo Sacramento, al tiempo que se repetía la lluvia de estampas y cédulas de la tarde anterior. A continuación se celebró una misa solemne. La capilla de la catedral la ilustró con sus cánticos, especialmente con un Gloria, «con tan acorde consonancia de voces y instrumentos que el más empedernido corazón en su obstinada dureza no pudo dejar de contemplar qué será la eterna, donde ángeles entonan el trisagio al Dios de los ejércitos" ${ }^{24}$. A la altura del Sanctus, la compañia de arcabuceros que ocupaba el atrio primero hizo una salva militar. Al sermón, subió al púlpito fray Antonio Navarro, lector de Vísperas en el convento de san Pablo; sustituía a fray Pedro de Montes, a quien se había dado el encargo, por haber enfermado inopinadamente. Su improvisado sermón sería publicado también junto con la Descripción... de donde tomamos nuestras informaciones.

A lo largo de la misa, la capilla de música «entretejió tres dulcísimos villancicos". Al acabar, se corrió una enorme cortina roja, que ocultó al Santísimo de la vista de la concurrencia. En la iglesia se hizo un espeso silencio: Al faltar el Santísimo, la atención de los presentes quedó sin objeto al que atender y buscó inmediatamente otra materia. El resto del templo se la ofreció: todo él había sido preparado para mostrar el montaje que, con aquella ocasión, los inquisidores tenían destinado para el ávido pueblo, quien ni siquiera se percató de que ya había pasado la hora de comer.

«Era más de la una del día y hallábanse tan embebecidos los ánimos que, recordando como de un suave letargo, al faltar materia en que se cebasen sus afectos, admiraron que el tiempo supiese deslizarse de entre las manos de la advertencia con pasos tan callados que ni aun de la necesidad humana déjase sentir» ${ }^{25}$.

${ }^{23}$ Ibidem. Descripción..., pág. Aa. Podría ponerse en duda si los Inquisidores de Córdoba tuvieron suficientemente en cuenta la segunda carta acordada remitida por el Consejo, en que se prohibian estos fuegos de artificio. Cfr. Apéndice VI.

${ }_{24}$ Ibidem. Descripción..., pág. Aa.

${ }_{25}$ Ibidem. Descripción..., págs. Aa-v. 


\section{LOS SOPORTES PLÁSTICOS Y LITERARIOS DE UN MENSAJJE}

La fiesta de la canonización de san Fernando significó, sin duda, para la Inquisición cordobesa, una excelente ocasión para comunicar al pueblo asistente e, indirectamente, al conjunto de la población cordobesa, un determinado mensaje que no se limitó, exclusivamente, a la notificación solemne de la decisión papal de incluir en el catálogo de los santos al rey Fernando III. En las fechas en que la Inquisición celebra su fiesta de san Fernando, la población está suficientemente al tanto de aquella noticia. Antes que la Inquisición, tanto el Cabildo de la ciudad como el Cabildo eclesiástico habian celebrado sendas fiestas, con el mismo objeto.

Así, los inquisidores pudieron aprovechar su propia celebración para ir un poco más lejos y para matizar el mensaje general con ciertas connotaciones orientadas a favorecer claramente a la Inquisición. En nuestra opinión, el mensaje que la Inquisición dirigió al pueblo pretendió inculcarle la idea de que la defensa de la fe y, concretamente, la Inquisición, eran necesarias para el Estado. Para llevar al pueblo hasta esta conclusión, lo condujeron por un sendero de numerosos, graduados y elocuentes símbolos, como vamos a ver.

El exterior del templo fue preparado adecuadamente. El atrio primero -un patio que aún puede verse ante la puerta principal, donde una escalinata salva el desnivel que desciende desde la calle hasta la puerta del templo-, se adornó con "verdes ramos de álamos blancos" ${ }^{26}$. Allí mismo se colocaron cinco banderas militares, la triunfal, la obsidional, la cívica, la mural y la naval. En la torrecilla que corona la puerta, se hicieron ondear tres gallardetes rojos. Sobre la torre principal, otros tres, del mismo color.

En el interior, las paredes de la iglesia fueron cubiertas con toda clase de colgaduras. La nobleza cordobesa prestó todos los paramentos necesarios para ello. "Para llenar el vasto vientre de su cuerpo y de sus capillas - cuenta la Descripción con estridente gusto barroco- se tragó dos mil piernas o bedeles de varias sedas este templo jayán» ${ }^{27}$.

${ }^{26}$ Jugando con el nombre latino del álamo blanco, populus, el autor de la Descripción consideró que este nombre presagiaba la muchedumbre de pueblo que asistiría a los actos. Descripción..., págs. Aa-v.

${ }_{27}$ Ibidem. Descripción..., págs. Aa-v. 
Bajo el arco del órgano, "se levantó un estrado de tres varas y media de alto». Sobre un sitial cubierto de paño de brocado de oro blanco, se colocó el Estandarte de san Fernando, bajo un rico dosel, "de que pendía una valiente pintura, efigie de Carlos II, Rey y Señor nuestro y dulce esperanza de sus leales vasallos, cuyos votos la prometen la posesión de ambos orbes" ${ }^{28}$. En el espacio que quedaba entre el estandarte y el retrato real, se colocó un risco contrahecho de dos varas de frente por otras dos de altura, en cuya cumbre aparecía un ave fénix de talla, colocada sobre una pira de «tan bien imitados leños ardientes que se persuadian verdaderos" ${ }^{29}$. Todo el conjunto quedaba entrelazado por guirnaldas de flores y ristras de frutos, todos ellos artificiales. Dos cipreses flanqueaban el conjunto, adornados con sendas panoplias con armas morunas ${ }^{30}$.

La capilla del Rosario también se había decorado ricamente. La adornaban dos estatuas "de valiente mano". Una representaba a la misericordia. Otra, a la justicia. Entre ambas, sostenían «una primorosísima cruz de plata, labrada de medio relieve de martillo, con los extremos dorados». El conjunto venía a representar, más que «las armas conocidas del tribunal de la fe, en la cruz, oliva y espada" un símbolo que daba a entender que este tribunal santo abría la puerta de los triunfos ${ }^{31}$. El principal triunfo concedido por la cruz a san Fernando no era otro que el de la conquista de la ciudad de Córdoba y éste era el hecho que se había representado en el ámbito de la capilla del Rosario: Formando perspectiva, valiéndose de tramoyas y bambalinas, se veía la ciudad, tal como se contempla desde el Campo de la Verdad. En primer término, el río Guadalquivir y el puente romano con la torre «que llaman de la Cerrajola» ${ }^{32}$. Más a lo lejos, se había figurado la puerta de la Puente. Todo el espacio descrito se veía ocupado por los ejércitos de Fernando III el Santo. El propio rey aparecía ante la torre del puente. Un ingenioso mecanismo hacía desfilar una interminable fila de soldados a caballo. A un lado, se admiraban los Alcázares, la torre del homenaje, la campana del Reloj, las casas obispales, los templos y torres de todas las iglesias de la ciudad, así como numerosas casas, «ilustrado todo de luces encubiertas» ${ }^{33}$.

${ }^{28}$ Ibidem. Descripción..., págs. Aa-v.

${ }^{29}$ Ibidem. Descripción..., págs. Aa-v.

${ }^{30}$ Ibidem. Descripción..., pág. B.

${ }^{31}$ Ibidem. Descripción..., pág. B.

${ }^{32}$ Actualmente se conoce como la Torre de la Calahorra. Descripción.... op. cit., pág. B.

${ }^{33}$ Ibidem. Descripción..., págs. B-v. 
Se describen en el relato que comentamos otros mil detalles del exorno de la iglesia, en los que no nos vamos a detener. En el altar mayor, donde estaba situada la custodia, el arte y el ingenio de los organizadores del festejo se habían excedido: Otro "misterioso" mecanismo hacía creer que una rueda de estrellas lucientes se movía continuamente a las espaldas de la custodia ${ }^{34}$.

No sólo se adornó el templo. El claustro entero se llenó de «inscripciones, prosas, versos, jeroglíficos e historias", que vinieron a complementar los objetivos «pedagógicos» de sus creadores.

Se ocupan las siguientes páginas de la Descripción de informar por menudo todas las maravillas que se habían plasmado en los espacios del claustro. Se da cuenta allí de las historias ${ }^{35}$, inscripciones ${ }^{36}$, quintillas ${ }^{37}$, sonetos ${ }^{38}$ y poemas en latín ${ }^{39}$ que llenaban el claustro. Allí se copian igualmente las «letras que se cantaron en las vísperas» y los textos de las "cédulas que se echaron en las estampas" ${ }^{40}$. Finalmente, se publicaba también en este folleto el Sermón que predicó el padre presentado Fr. Antonio Navarro... ${ }^{41}$.

\section{EL MENSAJE DE LA INQUISICIÓN AL PUEBLO}

Aunque la ocasión de organizar aquella gran fiesta la había dado la canonización de san Fernando, el propósito de los inquisidores no se limitó a celebrar el hecho en si, sino que, como dijimos, se aprovecharon de esta solemne circunstancia para comunicar al pueblo unos mensajes más precisos, orientados a ensalzar al Santo Oficio de la Inquisición. El que ideó aquel programa que luego se desplegó en formas arquitectónicas efímeras y en todo el conjunto de soportes informativos que se ofrecieron al público, procuró destacar aquellos aspectos de la vida del santo que más aptos parecieron a sus propósitos.

\footnotetext{
${ }^{34}$ Ibidem. Descripción..., págs. B-v.

35 Ibidem. Descripción..., págs. C-D.

${ }^{36}$ Ibidem. Descripción..., págs. Dv-F.

${ }^{37}$ Ibidem. Descripción..., pág. F.

${ }^{38}$ Ibidem. Descripción..., págs. F-G.

${ }^{39}$ Ibidem. Descripción..., págs. G-H.

40 Ibidem. Descripción..., págs. H-lav.

41 Ibidem. Descripción..., págs. K-Nv.
} 
Así, en primer lugar, se recalcó la relación, por no decir la identidad, existente entre el monarca reinante, Carlos II, y su antepasado, el rey san Fernando. Sirvió para mostrarlo uno de los tinglados que se montaron, concretamente, aquél en que, según hemos descrito, aparecían en un mismo escenario el estandarte de san Fernando y el retrato de Carlos II, unidos por el ave fénix sorprendida en el momento en que se consume en el fuego antes de renacer. El autor de la Descripción destacó el significado de esta escena en la forma siguiente:

«Formaban el concepto correspondiente a los deseos de nuestra lealtad, de ser Carlos Il el fénix renacido de las cenizas de Fernando el Tercero. ;Oh santo numen que en mejor imperio vives valido del Rey de los Reyes! Impetren tus ruegos de su divina Majestad, a la Majestad del Rey nuestro señor, tu decimocuarto nieto, que imite tus triunfos gloriosos, tu religión ardiente, tu caridad fervorosa... y que muera después de siglos con dilatada sucesión... tan santo que puedan los fieles en los venideros consagrarle semejante culto al que ahora te rendimos devotos".

... «Se brujuleaban ya los frutos que previene nuestra esperanza, pues se veían (empresa común de progenitor santo y descendiente glorioso) colocados a las dos puntas del estado, dos vividores cipreses, vestidos de armas y trofeos, en algunos carcajes, con flechas, turbantes turcos, alfanjes, arcos y adargas, representaron con mudas voces y a un tiempo mismo los triunfos con que el Santo Rey venció a los soberbios enemigos de la fe y al adversario antiguo del género humano y figuraron los despojos óptimos que no a Jove Feretrio, sino al Dios verdadero, más que algún vaticinio asegura, que ofrecerá al Rey nuestro Señor del Emperador bárbaro de los turcos, conquistando la Casa Santo; o quiera la Majestad divina que este Sol de España eclipse en el último deliquio las africanas lunas" ${ }^{42}$.

Dentro de este mismo propósito de identificar al monarca reinante con el festejado, nos parece que la primera de las Historias que se pintaron en el claustro encerraba una alusión especial a la regente doña Mariana de Austria, pues en ella se presentaba al rey san Fernando, siendo niño, en brazos de su madre doña Berenguela.

«Pintóse, - se nos dice en la Descripción-, a la señora reina Doña Berenguela, sentada en una rica silla, dando el pecho al santo rey,

42 Ibidem. Descripción..., pág. B. 
entonces tierno infante. En el cielo, en sitio correspondiente, una mano con señas que la llamaba. Fue la letra latina «NON VADAM, DONEC ADDATETUR PUER ET DUCAM" ${ }^{43}$.

La imagen y la frase seleccionadas traerían la convicción a quienes las vieran de que la reina madre, doña Mariana, trasunto de doña Berenguela, no dejaría abandonado a su hijo Carlos hasta que estuviera en condiciones de reinar ${ }^{44}$.

Identificados los dos personajes, el autor del programa da un segundo paso: Resaltar cuáles fueron los grandes triunfos alcanzados por san Fernando y llamar la atención sobre las causas que hicieron posible el que Dios premiara con aquellos triunfos a su siervo. Obviamente, su descendiente Carlos aparecería como llamado a obtener unos triunfos análogos, por los mismos medios por los que los obtuvo su antepasado.

Al explicar cuál fue la causa de aquellos triunfos, se trató de inculcar al pueblo la idea de que habían sido los esfuerzos de san Fernando en defensa de la fe los que le habian abierto la puerta del éxito. Para ello se levantó el tinglado de la capilla del Rosario, el cual, según vimos, enmarcaba con los símbolos de la Inquisición la escena de la conquista de Córdoba. La intención del autor fue explicitada por quien compuso la Descripción de la manera siguiente:

«No fue sólo vulgar representación de las armas conocidas del Tribunal de la fe en la cruz, oliva y espada, sino emblema sagrado y político que daba a entender que este Tribunal Santo abre la puerta de los triunfos ${ }^{45}$.

Una vez sentado que había sido la defensa de la fe la que había proporcionado los triunfos de san Fernando, podemos preguntarnos cuá-

${ }^{43}$ Cfr. Apéndice V.

${ }_{44}$ Dos años antes, en 1669, don Juan José de Austria había realizado su célebre marcha sobre Madrid. El padre Nithard, valido de la reina-gobernadora, había tenido que salir del país. Doña Mariana, sin embargo, retuvo la regencia.

${ }_{45}$ Descripción, pág. B. En la boca de este escenario, se sentaron dos ministros del tribunal, ante un «bufete cubierto de sobremesa carmesí», quienes "repartieron limosna a los sacerdotes que en gran número concurrieron a decir misa desde el rayar del alba hasta la una del día, por la intención que se les había advertido; fue de que diesen gracias a nuestro señor...y concediese al Rey nuestro señor y a la Reina nuestra señora (Atlante ahora del peso de dos mundos, por nuestra mejor dicha) dilatados años de vida, colmando de felicidades su venturoso siglo». (Ibidem, pág. Bv). 
les eran esos triunfos $\mathrm{o}$, al menos, cuáles consideraron los inquisidores que debían resaltarse, para lograr el fin que perseguían.

Como triunfos se consideraban la fidelidad de sus vasallos al rey san Fernando; la restitución a Compostela de las campanas robadas por Almanzor; su victoria sobre los moros en Murcia, en la que una cohorte angélica vino en ayuda de las tropas cristianas; la intervención de Santiago Matamoros en la batalla de Jerez; o la batalla de Segura de la Sierra, en la que se supone que san Fernando detuvo la carrera del Sol, como nuevo Gedeón. Como ejemplo del «espíritu inquisitorial» de san Fernando, otras dos pinturas revivieron el recuerdo de cómo el santo rey hizo quemar a la mujer libidinosa que tentó a santo Domingo, y el Auto de $\mathrm{Fe}$ en que el propio rey echó haces de leña a la hoguera en que eran quemados los herejes ${ }^{46}$.

La defensa de la fe contra herejes y moros que tan ejemplarmente se supone que llevó a cabo san Fernando, no puede menos que ser continuada por sus sucesores en el presente, concretamente, por Carlos II, quien, al fin y al cabo, no sería sino el propio Fernando, renacido de sus cenizas, como el ave fénix. Así se explicita en uno de los sonetos expuestos:

«Oh, fénix de virtud, a cuyo santo celo, la religión más pura y clara España debe, cuya fe eternizas.

Esa fe en tus reliquias arde tanto que, si acaso en tus reinos se apagara, bastaran a encenderla tus cenizas ${ }^{47}$.

Como digno sucesor de san Fernando, el monarca a la sazón reinante debería, en consecuencia, proteger la fe de su pueblo, mediante la Inquisición y extender las fronteras de la fe cristiana, luchando contra el Islam. En unos momentos en que el principal peligro para la fe viene, precisamente, del exterior, no faltan constantes alusiones a la lucha contra la Media Luna.

Pocos años antes, en 1668, los turcos habían conquistado la isla de Creta, firme bastión en las defensas de la Cristiandad. Poderosos ejércitos turcos avanzaban también hacia la católica Polonia, en un movimiento amenazante que sólo se conjuró en 1673, tras la famosa victoria del

\footnotetext{
${ }^{46}$ Descripción, págs. C-Cav
}

${ }^{47}$ Cfr. Apéndice IX. 
polaco Sobieski sobre los turcos. Pero en 1671 , fecha en que se realiza la fiesta que comentamos, se vive en tensión en toda la Cristiandad. No es de extrañar, pues, la insistencia de quienes organizaron aquel solemne acto de culto a san Fernando, gran vencedor de musulmanes, en atraer la atención de quien viene a ser algo así como la reencarnación de san Fernando, el monarca reinante, sobre la conveniencia de atajar el avance turco.

En la rica batería de jeroglíficos que se ofrecieron al pueblo, no faltó uno que aludiese a la Luna eclipsada por el Sol, en clara alusión a lo que venimos diciendo ${ }^{48}$. Ni otro en que se presentaba «un elefante que, en señas de adoración, alzaba la probóscide al Sol»:

«Su Luna adore el impío sarraceno,
que Fernando, elefante más piadoso,
a solo Cristo adora, Sol hermoso" ${ }^{49}$.

La defensa de la fe mediante la guerra contra la Media Luna en el exterior y, en el interior, por la acción de la Inquisición, vendría a ser la misión que correspondía realizar al monarca reinante, a imitación de san Fernando. Ésta habría sido la más alta gloria del santo rey, gloria que nadie había demostrado tan palmariamente como el Santo Oficio de la Inquisición. Por si cabía alguna duda, el fraile que improvisó el sermón no se recató en comparar a los inquisidores con los discípulos predilectos de Cristo:

"¿A quién se le encarga, —dijo-, que a su tiempo manifieste y publique a todo el mundo la santidad de Cristo? ¿Se le encarga a todos los discípulos? No por cierto. A solos Pedro, Juan y Diego, con especialidad, se les encarga el desempeño de aquesa acción. Y ¿Por qué más a éstos que a los demás discípulos? ¿Saben por qué? Porque éstos eran «los del secreto», que por esto dice Teofilato los escogió la Majestad de Cristo, porque eran entre todos los de más secreto...Y asi, a esos solos les encarga Cristo que no publiquen sus glorias hasta que sea tiempo. Fiando que ellos, en la ocasión, sabrian mejor que todos

${ }^{48}$ Cfr. Apéndice VI.

${ }^{49}$ Descripción, pág. Cav. Casi todos los jeroglíficos que se elaboraron corresponden a los que estamos acostumbrados a encontrar en los clásicos de la emblemática. Algunos de ellos aparecen entre los Emblemas morales de Sebastián de Covarrubias. Otros son similares a algunos de los que aparecen en las Empresas Morales de Juan de Borja. Los lemas y el sentido de las glosas, sin embargo, difieren de las que aparecen en las obras citadas, pues se han acomodado, generalmente, a la intención que presidió este programa didáctico, elaborado bajo la inspiración de la Inquisición cordobesa. 
desempeñar la acción, porque ningunos se desempeñan con más liberalidad en sus obras que los que son avarientos en las palabras. Con esto no me parece tengo necesidad de individuar el asunto a la ocasión presente, cuando tan calificada se ve su verdad en tan magnífica demostración, como hoy ejecuta este Santo Tribunal» ${ }^{50}$.

La fiesta que organizó la Inquisición de Córdoba con ocasión de la canonización de san Fernando, se nos presenta, pues, como un acontecimiento típicamente barroco. En ella captamos el esfuerzo denodado de una de las más significadas instituciones de la Iglesia contrarreformista por atraer la atención del pueblo fiel e inculcarle unas determinadas ideas. No se perdonan esfuerzos, no se frena la imaginación, no se escatiman recursos, para lograr este propósito. No importa que, en realidad, aquel Carlos II o aquella reina-gobernadora, a quienes se presenta como atlantes que sostienen el orbe sobre sus hombros, fueran dos tristes personajes, débiles, frágiles o enfermos. Como no importaba la veracidad histórica de las muchas leyendas que se habían acumulado para ensalzar la figura de san Fernando. Consideramos que es propio del espíritu del barroco católico eclesiástico este proselitismo militante y triunfalista del que se hizo gala en la fiesta de san Fernando y que la Descripción de la misma, que nos ha servido de guía en este trabajo, es una signficativa prueba del afán de los dirigentes de la época, en este caso los inquisidores de Córdoba, por mantener la adhesión del pueblo a los modelos ideológico-religiosos de la Contrarreforma.

${ }^{50}$ Descripción, pág. Nv. 


\section{APÉNDICES}

I

BULA ADUTURAM REI MEMORIAM de Clemente X, del día 7 de febrero de 1671, por la que autoriza el culto público a Fernando III el Santo.

"Clemens Papa X. Ad futuram rei memoriam. Gloriosissimos coelestis Hierusalem cives, illos praesertim qui in diebus peregrinationis suae, tametsi in rerum humanarum sublimitate positi essent, non sperarunt in lubrico divitiarum, nec in regiae potentiae dignitate, sed magna illa virtute humilitatis, qua, - sicut omnia terrena cacumina temporali nobilitate nutantia non humano usurpata fastu, sed divina gratia donata celsitudo transcendat--, solidati bellarunt bella Domini et unico illi fundamento, quod est Christus lesus, innixi, superaedificarunt aurum, argentum, lapides praetiosos, manentisque operis mercedem in aeternae salutis stabilitate accipere meruerunt, congruis honorum, laudumque praeconiis in terris coelebrandos esse merito censemus; ac proinde, flagitantia indipsum regum orthodoxorum non minus pietatis aliarumque christianarum virtutum quam regii fastigii splendore fulgentium vota paterno affectu exaudimus, sicut ad Ecclesiae Cátholicae decus, spiritualemque fidelium populorum aedificationem, atque devotionem fovendam et promovendam, conducibile in Domino fore arbitramur. Cum itaque alias, videlicet, die XXIX maii MDCLV Congregatio tunc exsistentium S.E.R. Cardinalium Ritibus Praepositorum ex deductis in processu auctoritate Apostolica confecto super casu excepto declaraverit de illo constare ex cultu exhibito servo Dei Ferdinando III, Regi Castellae et Legionis, cognomento Sancto per inmemorabilem temporis cursum excedentem metam centum annorum ante Decreta fel.rec.Urbani Papae VIII, praedecessoris nostri cum scientia, vel tolerantia Ordinariorum et emanatum desuper dictae Congregationis Decretum re.mem., Alexander Papa VII, etiam praedecessor noster, die XXXI eiusdem mensis approbaverit et inter alia plenissme constiterit de celebratione missarum in honorem praedicti Servi Dei, prout de sanctis celebrari solent tam in Sacrario veteri quam in capella Beatae Mariae Regum nuncupata Metropolitanae Ecclesiae Hispalensis, ubi exstat illius sepulchrum. Hinc est quod nos piis ennixisque charissimi in Christo filli nostri Caroli Hispaniarum Regis Catholici, ac charissimae in Christo filiae nostrae Mariannae, earundem Hispaniarum Reginae Catholicae viduae eius Genitricis praecibus nobis per dilectum filium nobilem virum Petrum de Aragonia, Ducem Segorbiae et Cardonae, Regni Neapolitani Proregem 
ac eiusdem Caroli Regis apud nos et Sedem Apostolicam oratorem ad praestandam nobis ipsius Caroli Regis nomine aboedientiam missum super hoc humiliter porrectis, favorabilem assensum cum Domino possumus praebere, cupientes ut in omnibus Regnis Hispaniarum et Ditionibus eidem Carolo Regi subiectis et in Ecclesia SS.lacobi et Ildephonsi de Urbe nationis Hispanorum de memorato servo Dei Ferdinando Tertio Rege, missa et officium de communi confessorum non Pontificum sub ritu duplici iuxta rubricas breviarii et missalis romani quotannis in perpetumm die XXX maii qua idem servus Dei obdormivit in Domino, celebrari et ab omnibus utriusque sexus Christi fidelibus qui ad Horas canonicas tenentur, recitare libere et licite possint et valeant respective, aucthoritate Apostolica tenere praesentium concedimus et indulgemus. Non obstantibus Costitutionibus et ordinationibus apostolicis, ac Decretis, caeterisque contrariis quibuscumque. Volumus autem ut earumdem praesentium litterarum transumptis seu exemplis etiam impressis, manu alicuius notarii publici subscriptis et sigillo personae in Ecclesiastica dignitate constitutae munitus, eadem prorsum fides ab omnibus et ubique tam in iudicio quam extra illud habeatur quae haberetur ipsis praesentibus si forent exhibitae vel ostensae. Dat. Romae apud S. Mariam Maiorem sub Annulo Piscatoris die VII februarii MDCLXXI, Pontificatus nostri anno primo. I. G. Slusius».

Real Cédula de la Reina Gobernadora, D. ${ }^{a}$ Mariana de Austria, dirigida a la ciudad de Córdoba el 23 de marzo de 1671 por la que le envía copias autorizadas del Decreto y Breve de S. S. Clemente X para que se celebre la fiesta de san Fernando en todos los dominios de la Corona y se hagan demostraciones de alegría el día de su festividad, 30 de mayo. Archivo Municipal de Córdoba, Asuntos religiosos, Sc. 3. ${ }^{a}$, se. $1 .^{a}$, San Fernando, Rey de España, n. 2

"Concejo, justicia, veinticuatros, caballeros, jurados, escuderos, oficiales y hombres buenos de la muy noble y leal Ciudad de Córdoba. Habiendo concedido S. S., a mi instancia, breve para que el día que murió el santo rey don Fernando el tercero se celebre en todos los reinos y dominios del rey don Carlos, mi muy caro y amado hijo, asimismo un Decreto para que este presente año se pueda celebrar la festividad... como uno y otro veréis de las copias de dichos breve y decreto que se remiten con ésta y, siendo este suceso por todas razones tan digno del 
mayor contento y regocijo, como reconoceréis y que en mí ha causado muy particular por haberse logrado en tiempo que está a mi cargo el gobierno de estos reinos, buscando que se manifieste en todos ellos con las demostraciones debidas al rey de Castilla y santo, os mando que en esta consideración y en conformidad con los dichos breve y decreto, dispongáis que en esa Ciudad se haga toda demostración... y que el día que se señalare para que se haga su festividad concurráis a su culto con el mayor lucimiento público que se debe a tan feliz suceso y alborozo con que debe estar la Monarquía de haberse conseguido dichos breve y decreto, que así lo espero de vuestra atención y de que me daréis de los que obrareis a manos de don Iñigo Fernandez del Campo, del Consejo y Secretario en él de la Cámara del Patronazgo Real. De Madrid a 23 de marzo de 1671.-Yo, la Reina".

Fragmento de la Carta Acordada remitida por el Consejo a los Tribunales de distrito el 4 de julio de 1671, ordenando la celebración de la fiesta de San Fernando. AHN, Inquisición, lib. 497, fols. $192 \mathrm{r}-193 \mathrm{r}$

«La Reina nuestra señora (que Dios guarde), con su real decreto de 3 de este mes, se ha servido remitir al Consejo copias auténticas del breve y decreto de Su Santidad, en que concede a todos los reinos y dominios del Rey nuestro señor la misa y rezo con ritu* doble del santo rey don Fernando, para el día 30 de mayo de cada año (que fue en el que murió), permitiendo que el primer año se pueda celebrar esta festividad el día que se eligiere. Para que este Consejo por lo que le toca, disponga se envíe a las partes donde (192v) convenga a fin de que tengan el debido cumplimiento y observancia y manda S. M. (entre otras demostraciones) que todos los Consejos, cada uno por sí y en día distinto, hagan fiesta con misa y sermón al santo, como se hizo en la festividad de la Concepción y en otras, comenzando desde los 25 de junio en adelante. $Y$ visto, presente el Excmo. Sr. Obispo de Plasencia, Inquisidor General, ha parecido remitiros copia del breve y decreto de Su Santidad, de las que envió al consejo S. M. y ordenaros que en un día, el que os pareciere, como sea después del referido 15 de junio, hagáis esta fiesta al santo rey en la iglesia donde se suelen celebrar las demás festividades por ese tribunal, conforme a lo que se hizo en la del beato Pedro de Arbués. Y del recibo de (193) esta orden y del día en que se podrá hacer 
esta festividad, daréis cuenta al Consejo. Dios os guarde. Madrid, a 4 de mayo 1671. Señores Castejón, Villegas, Ayala, Valenzuela».

\section{IV}

Fragmento de la Carta Acordada remitida por el Consejo a los Tribunales de distrito el 1 de junio de 1671, dando detalles sobre cómo ha de celebrarse la fiesta de San Fernando. AHN, Inquisición, lib. 497, fol. $193 \mathrm{v}$

"Aunque en carta de 4 del pasado se os ordenó hiciésedes la fiesta del santo Rey don Fernando conforme a la que se hizo al beato Pedro de Arbúes, consultado con el Excm. Sr. Obispo de Plasencia, Inquisidor General, ha parecido advertiros que la fiesta del santo rey se ha de hacer solamente con misa, música y sermón y el ornato necesario de altar e iglesia, poniendo la noche antes luminarias, pero sin envención de fuegos. Y del recibo de esta orden avisaréis luego al Consejo. dios os guarde. Madrid a 1 de junio de 1671. Caballero, Villegas, Ayala, Valenzuela».

\section{$\mathrm{V}$ \\ HISTORIAS}

Reproducimos una de las «Historias» que se detallan en la Descripción... Cfr. pág. C.

"Pintóse a la Señora Reina doña Berenguela, sentada en una rica silla, dando el pecho al santo Rey, entonces tierno infante, en el cielo, en sitio correspondiente, una mano con señas que la llamaba. Fue la letra latina Non vadam, donec addatetur puer, et ducam eum ut appareat ante conspectum Domini et magneat in vaqiter (I Reyes, 7).

Con piedad desusada si alimenta al tierno infante madre generosa, el cándido licor que le apacienta sangre dará a su espada victoriosa.

De la diosa de amor planta sangrienta si en roja convirtió la blanca rosa, Venus casta a Cupido más severo más bello criará cuanto más fiero". 


\title{
$\mathrm{VI}$ \\ HIEROGLÍFICOS
}

Descripción..., pág. C2

«Pintóse una Luna eclisada, el Sol dentro de su medio círculo y la Tierra bañada de sombras. Decían las letras:

ORIETUR IN TENEBRIS LUX

Eclipse a Luna africana

El Sol que, con mejor vuelo, penetró el último cielo".

\section{VII \\ INSCRIPCIONES}

Descripción..., pág. Dv.

\author{
FERDINANDO TERTIO \\ "Castellae et Legionis Regi,
}

Murgiano, Giennensi, Cordobensi, Hispalensi, Strenuo, Audaci, Bellicoso, Propugnatori, Forti, lusto, Clementi, Pio, Liberalis, Benefico, Felici, Magnanimo, Famigerato, Maximo, Patriae Patri, (HAEC UT REX)

Caeloti Religioso, Poenitenti, Ellemosynario, Abstinenti, Casto, Extatico, Deo et hominibus dilecto

(HAEC ET ALIA UT SAN ${ }_{i} C_{i}$ TUS)

Sanctum Inquisitionis Tribunal Cordubense

Vicem rependens illius Religiosi obsequiii, quo

Ferdinandus

(Pia sarcina)

Ligna humeris baiulans

lustae haeresios vindictae ministravit, HOC OBSEQUIUM REGI, ET SANCTO

Devotionis ut sancto, reverentiae ut regi

Pedibus eius provolutum curavit». 


\section{VIII \\ QUINTILLAS}

Descripción..., pág. $\mathrm{F}$

Muy niño, Fernando gira

en la oración sus antojos

tanto que el mundo le admira

de que ponga en Dios la mira

cuando no ha abierto los ojos.

En la oración se adelanta

Fernando con gran desvelo

de tan poca edad que el cielo

en éxtasis lo levanta

cuando no se ve en el suelo.

De un éxtasis que le guía

Fernando llega a poder

del moro, mas sin querer, como éste lo aborrecia, nunca lo podía ver.

Tanto al moro avasallaba de Fernando la oración, que probó en cierta ocasión, ser el rey quien lo postraba sólo por contemplación.

Cuando a impulsos soberanos a Dios Fernando con alma contempla, puestas las manos, sus ejércitos ufanos del moro alcanzan la palam.

Viendo Fernando, advertido que el moro guerra le ofrece, en la oración recogido, arrodillado, merece que el moro quede rendido.

Como los moros sabían que, cuando Fernando estaba en oración, perecian, ninguno lo deseaba, aunque por eso morían.

Siendo Fernando el crisol de Josué, la fortuna que éste consiguió oportuna tuvo, pues, parando al sol, se dejó el moro a la luna. 
Tanto Fernando sentía

el crimen de la herejía

que, en teniendo alguna luz del que en la fe delinquia, luego le hacía la cruz.

Tan devoto en la oración fue Fernando que ajustaba su cuenta con Dios y hallaba por su contemplación al mismo Dios alcanzaba.

\section{IX SONETOS}

Selección tomada de la Descripción..., pág. Fv.

«Al detenerse el sol, para que el Josué de la Ley de Gracia, Fernando, alcanzara un triunfo de los moros, en ocasión que le iban ya embarazando las sombras».

El Sol, flamante antorcha de los días, Fernando, porque ensalces tus banderas, oprime el freno a sus lucientes fieras, fieras al moro si al cristiano pías.

O a mirar se paró cómo vencías, o a darte el curso para que vencieras, que dar alcance a lunas tan ligeras con el curso del sol sólo podías.

Si ya no es que el pundonor le para que, como a tanta luna en la conquista ahuyenta gloriosa tu fortuna, el sol mismo temió que se afirmara si vuelve las espaldas a tu vista, que de tí huye el sol como la luna.

«Al haber llevado el Santo Rey la leña sobre sus hombros para quemar a un hereje».

Mano de Abraham fiel, de Isac robusto, hombo atlánteo, siempre al Sacro Oficio convierte, con católico ejercicio la impía ofrenda en holocausto justo. 
No así el ave que usurpa en clima adusto vital aliento al funeral suplicio, aromático al cielo sacrificio da, cual la hazaña de Fernando Augusto.

Oh fénix de virtud, a cuyo santo celo la religión más pura y clara España debe, cuya fe eternizas.

Esa fe en tus reliquias arde tanto que si acaso en tus reinos se apagara, bastara a encenderla tus cenizas».

«A ruegos del Santo Rey, bajaron los ángeles a ayudar nuestro campo en la conquista de Murcia».
Alborotó Luzbel el sacro asiento donde la paz y la quietud reposa $y$ de Dios la milicia belicosa le fulminó del alto firmamento.
Con menor fuerza y con igual aliento mueve las armas la nación odiosa contra Fernando y baja presurosa a convertir su orgullo en escarmiento.
Un mismo escuadrón veo peleando por su Dios y Fernando, porque ha sido una la causa de uno y otro bando.
Uno y otro es del cielo obedecido ¡Oh Dios! ¿Tienes acaso con Fernando el imperio del cielo dividido?

\section{$x$ \\ SEGUIDILLAS}

Estribillo De un monarca y un Santo cuento la vida.

Son una misma.

Oigan,

Atiendan,

en seguidillas, virtudes conquistas

que se fue Narciso en pureza, en victorias es maravilla. 
Seguidillas Este santo en su vida fue de corona; mas ya tiene en el cielo grados de gloria.

Tuvo historias con moros por la fe sola.

$Y$ hoy por el cronista tiene otra historia.

En la Virgen hallaba pronto el Remedio con que hacia de malos buenos sucesos.

Muchas de sus victorias tuvo previstas $y$, con ser reveladas, no se perdían.

Que aunque rey, trabajaba, dicen judíos

y aunque más lo mormuren fue un santo oficio.

Que ellos tienen la culpa, vistos los autos, lo dirá un san Benito con un san Pablo.

Que ganó muchas tierras no duda nadie, que es verdad que la prueban muchos lugares.

Aunque un rasgo es lo escripto tiene disculpa, porque sólo los rasgos toca a las plumas. 